\title{
The Zebrafish ennui Behavioral Mutation Disrupts Acetylcholine Receptor Localization and Motor Axon Stability
}

\author{
Louis Saint-Amant, ${ }^{1 \star}$ Shawn M. Sprague, ${ }^{1}$ Hiromi Hirata, ${ }^{1 \dagger}$ Qin $\mathrm{Li}^{1 *}$ \\ Wilson W. Cui, ${ }^{2}$ Weibin Zhou, ${ }^{1}$ Olivier Poudou, ${ }^{3}$ Richard I. Hume, ${ }^{1}$ \\ John Y. Kuwada ${ }^{1,2}$ \\ ${ }^{1}$ Department of Molecular, Cellular and Developmental Biology, University of Michigan, Michigan \\ ${ }^{2}$ Cell and Molecular Biology Graduate Program, University of Michigan, Michigan \\ ${ }^{3}$ Department of Mechanical Engineering, University of Michigan, Michigan
}

Received 26 June 2007; accepted 29 July 2007

\begin{abstract}
The zebrafish ennui mutation was identified from a mutagenesis screen for defects in early behavior. Homozygous ennui embryos swam more slowly than wild-type siblings but normal swimming recovered during larval stages and homozygous mutants survived until adulthood. Electrophysiological recordings from motoneurons and muscles suggested that the motor output of the CNS following mechanosensory stimulation was normal in ennui, but the synaptic currents at the neuromuscular junction were significantly reduced. Analysis of acetylcholine receptors (AChRs) in ennui muscles showed a marked reduction in the size of synaptic clusters and their aberrant localization at the myotome segment borders of fast twitch muscle. Prepatterned, nerve-independent AChR clusters appeared nor-
\end{abstract}

mal in mutant embryos and dispersed upon outgrowth of motor axons onto the muscles. Genetic mosaic analysis showed that ennui is required cell autonomously in muscle fibers for normal synaptic localization of AChRs. Furthermore, exogenous agrin failed to induce AChR aggregation, suggesting that ennui is crucial for agrin function. Finally, motor axons branched more extensively in ennui fast twitch muscles especially in the region of the myotome borders. These results suggest that ennui is important for nerve-dependent AChR clustering and the stability of axon growth. (c) 2007 Wiley Periodicals, Inc. Develop Neurobiol 68: 45-61, 2008

Keywords: development; neuromuscular; mutant; acetylcholine; synapse
*Present address: Pathologie et Biologie Cellulaire, Université de Montréal, Montréal, Canada.

$\dagger$ Present address: University of Nagoya, Nagoya, Japan.

${ }^{\$}$ Present address: HHMI, UCLA, California.

Correspondence to: J.Y. Kuwada (kuwada@umich.edu).

Contract grant sponsor: NINDS; contract grant number: NS36587.

Contract grant sponsor: University of Michigan Center for Organogenesis Training, NIH; contract grant number: 5-T32-HD007505.

Contract grant sponsor: Fonds de la Recherche en Santé du Québec.

(c) 2007 Wiley Periodicals, Inc.

Published online 4 October 2007 in Wiley InterScience (www. interscience.wiley.com).

DOI 10.1002/dneu.20569

\section{INTRODUCTION}

The survival of animals depends on the reliability of motor outputs. An essential component of this reliability is the neuromuscular junction (Sanes and Lichtman, 1999; Slater, 2003). The NMJ consists of the close apposition of presynaptic motor axon terminals, which contain acetylcholine (ACh) filled synaptic vesicles, with specialized postsynaptic structures that display a very high density of ACh receptors (Sanes and Lichtman, 1999). Prior to innervation embryonic muscles contain nerve independent or aneural 
clusters of analysis of acetylcholine receptors (AChRs). Subsequently, motor axons extend upon muscles and induce nerve dependent AChR clusters at the incipient NMJ and disperse non-synaptic AChR clusters (Madhavan and Peng, 2005). The induction of AChR aggregates at the NMJ requires zagrin, a neural specific form of a heparan sulfate proteoglycan that is secreted by the motor axons and is both necessary and sufficient for nerve dependent aggregation of AChR clusters (Godfrey et al., 1984; Ferns and Hall, 1992; Hoch et al., 1994; Gautam et al., 1996). Agrin is thought to act through a postsynaptic receptor complex that includes MuSK and Rapsyn, both of which are crucial for nerve independent as well as nerve dependent clustering of AChR (Gautam et al., 1995; DeChiara et al., 1996; Fuhrer et al., 1999). However there are still are gaps in our understanding of the mechanism by which prepatterned clusters are consolidated by the motor axon and the molecular signaling pathway initiated by zagrin. Indeed, MuSK has long been speculated to require an unknown coreceptor, for agrin binding, named Myotube Associated Specificity Component (MASC) (Glass et al., 1997). In addition, results in Drosophila suggest the action of retrograde signals from muscle fibers to motor axons during NMJ formation (Haghighi et al., 2003; Keshishian and Kim, 2004), but it remains to be determined whether this also occurs in vertebrates. Finally, novel proteins, such as DOK-7 and LRP4, have recently been shown to be strictly required for cluster formation at the NMJ (Okada et al., 2006; Weatherbee et al., 2006). These facts strengthen the concept that there is still much to be discovered at the NMJ.

One of the best ways to uncover new genetic mechanisms in development is to perform forward genetics as mutagenesis screens offer an unbiased approach towards gene discovery. We have performed an ENU mutagenesis screen for motor behavior defects in embryonic zebrafish. The zebrafish offers many advantages as a genetic model. Indeed, the accessibility during embryonic stages and optical clarity of the zebrafish embryo has enabled a detailed, dynamic analysis of the earliest steps in the formation of the vertebrate NMJ (Westerfield et al., 1990; Flanagan-Steet et al., 2005; Panzer et al., 2005). These studies demonstrated that as is the case in mammals motor growth cones initially extend upon muscles that have nerve independent clusters of AChR that form in the midregion of the muscle fibers. The dynamic analysis showed that motor growth cones preferentially extend toward these prepatterned clusters and consolidate them into stable NMJs (Flanagan-Steet et al., 2005; Panzer et al., 2006).
Thus, muscles play a much more active role in the initiation of the NMJ formation than previously appreciated. These and other studies are shedding light on the development of the NMJ but the exact molecular nature of the interaction between motor axons and muscle cells during the formation and maintenance of the NMJ remains unclear.

This work describes a novel zebrafish mutant, ennui, which was isolated in a mutagenesis screen for motility defects. The motor defect is due to a dramatic decrease in synaptic clustering of AChRs and extensive mislocalization of AChRs at the ends of muscle fibers along the myotomal boundaries during embryonic stages. The mislocalization of AChRs in mutants is cell-autonomous suggesting that the ennui gene is required in muscles. Interestingly, prepatterned, nerve-independent AChR clusters are normal in mutants but are quickly dispersed upon outgrowth of motor axons into the myotomes and the motor axons exhibit a marked over branching phenotype at later stages. Thus the ennui mutation seems to disrupt the interaction between the motor axon and the muscle cells, which leads to a lack of consolidation of the prepatterned clusters of AChRs into a stable NMJ suggesting that the ennui gene may play an important role in the initiation and maintenance of the NMJ.

\section{METHODS}

\section{Animals}

Zebrafish were bred and raised according to established procedures (Westerfield, 2000) which meet the guidelines set forth by the University of Michigan animal care and use protocols. The ennui $\left(\right.$ nui $\left.^{\text {mi36 }}\right)$ line was isolated from a mutant screen for motor defects of inbred ENU mutagenized F2 families which were generated following protocols described for previous screens (Haffter et al., 1996).

\section{Behavioral Analysis}

Techniques for analysis of embryonic behaviors were described previously (Saint-Amant and Drapeau, 1998). Briefly, movements of the embryos and larvae were recorded using a CCD camera (Panasonic wv-bp330) mounted on a dissection microscope and a VCR (Panasonic S-VHS). Swimming speed was assessed by measuring linear head displacement between video frames during a swimming bout in a large Petri dish using NIH image software. In some cases fish were restrained to observe swimming movements by first anesthetizing them in a solution containing $0.01 \%$ MS222 (Sigma) and their heads embedded in low melting point $\left(26^{\circ} \mathrm{C}\right)$ agarose $(0.5-1.0 \%$, Gibco $\mathrm{BRL})$. The embedded fish were then immersed in anes- 
thetic-free solution and allowed to recover to videotape their swimming.

\section{Assessment of Contraction Strength In Vivo}

Swimming episodes were initiated in eight embryos and 22 successive frames $(30 \mathrm{~Hz})$ were obtained during the swimming episode. For each frame the $X-Y$ coordinates for 6 points along the tail were assayed. A third order, parametric interpolation of these data yields a continuous representation of the tail's geometry, which helps represent the coordinates of any point of the tail with two functions $x(s)$ and $y(s), s$ varying between 0 and $n$. The length of the tail is calculated using the formula:

$$
L=\int_{0}^{n} \sqrt{\left(\frac{\mathrm{d} x}{\mathrm{~d} s}\right)^{2}+\left(\frac{\mathrm{d} y}{\mathrm{~d} s}\right)^{2}} \mathrm{~d} s
$$

The tail mobility index observed for this frame is calculated as the average value along the tail of the square of the inverse of the radius of curvature $r$. This formula is based on a mechanical analogy: the square of the inverse of the radius of curvature of a beam is related to the amount of strain energy required to produce such a deformation. The tail mobility index calculated at the $i$-th frame is therefore given by the formula:

$$
M_{i}=\frac{1}{L} \int_{0}^{n} \frac{\left(\frac{\mathrm{d} x}{\mathrm{~d} s} \frac{\mathrm{d}^{2} y}{\mathrm{~d} s^{2}}-\frac{\mathrm{d} y}{\mathrm{~d} s} \frac{\mathrm{d}^{2} x}{\mathrm{~d} s^{2}}\right)^{2}}{\left(\left(\frac{\mathrm{d} x}{\mathrm{~d} s}\right)^{2}+\left(\frac{\mathrm{d} y}{\mathrm{~d} s}\right)^{2}\right)^{3}} \mathrm{~d} s
$$

A high potassium solution was used to bypass the NMJ and directly test the capacity of muscle cells to contract in response to a depolarization. Thirty-six-hour-old embryos were pinned in a sylgard coated Petri dish containing extracellular bathing solution (see electrophysiology later) and anesthetic $(0.01 \%$ MS222) and skinned on one side. Isotonic $\mathrm{KCl}(150 \mathrm{mM})$ was ejected from a pipette onto an exposed axial myotome and the resulting contraction was measured as the percentage reduction in length of the myotome as compared with the pre-ejection length.

\section{Electrophysiology}

Electrophysiological techniques were described previously (Drapeau et al., 1999; Buss and Drapeau, 2000; SaintAmant and Drapeau, 2003). Briefly, embryos were anesthetized with tricaine $(0.02 \%$, sigma, St-Louis $)$, pinned to a sylgard coated dish and bathed in extracellular recording solution (in $\mathrm{m} M$ ): $134 \mathrm{NaCl} ; 2.9 \mathrm{KCl} ; 2.1 \mathrm{CaCl}_{2} ; 1.2$ $\mathrm{MgCl}_{2} ; 10$ glucose; $\mathrm{pH} 7.8$. The skin overlying several segments was peeled off for access to muscle cells. For motoneuron recordings the preparation was further treated with collagenase (typeXI, $0.02 \%$ ) to loosen the musculature for easier removal of muscle cells and exposure of the spinal cord. The identity of the neurons was verified from their morphology following labeling with $0.1 \%$ sulforhodamineB (Sigma Chemical) that was included in the patch pipette. The bath solution contained $15 \mu M d$-tubocurarine to completely paralyze the animals to record motoneuron activity during fictive swimming. During muscle recordings less $d$ tubocurarine (3-7 $\mu M$ ) was added to partially block of NMJ currents to allow for recording of synaptic activity at the NMJ while effectively blocking muscle contraction. In some experiments tetrodotoxin (TTX, $1 \mu M$; Sigma, St-Louis) was used to block action potentials.

We used standard whole-cell recording techniques (Hamill et al., 1981) in vivo at room temperature $\left(22^{\circ} \mathrm{C}\right)$. Patch-clamp electrodes were pulled from thin-walled, Kimax-51 borosilicate glass ( 5-12 $\mathrm{M} \Omega$ resistance) and were filled with (in $\mathrm{mM}$ ) : $105 \mathrm{~K}$-Gluconate; $16 \mathrm{KCl} ; 2$ $\mathrm{MgCl}_{2} ; 10$ HEPES; 10 EGTA; 4 NaATP; pH 7.2, which had junction potentials of $6 \mathrm{mV}$ that was not corrected for. Whole-cell voltage or current was recorded with an Axopatch-1A or -1D amplifier (Axon Instruments) filtered at 2$5 \mathrm{kHz}(-3 \mathrm{~dB})$ and digitized at $20-50 \mathrm{kHz}$. Data were acquired with pClamp 9.0 software (Axon Instruments) and were analyzed off-line with pClamp 9.0 (Axon Instruments). Tactile stimulation was delivered via a liquid ejection through a glass pipette. The stimulation duration and intensity were controlled by a picospritzer 2 (Parker Instrumentation). Miniature event were detected using the template detect function of clampfit 9 and their frequency was determined by dividing the number of events by the total recording time.

\section{Immunostaining}

Motor axon projections were labeled with anti-SV2 (Hybridoma bank, Iowa City; 1:100) and an Alexa Fluor 488conjugated anti mouse IgG secondary antibody (Molecular Probes, Invitrogen, Carlsbad; 1:1000). AChRs were labeled with $\alpha$-bungarotoxin (BTX) conjugated with Alexa Fluor 594 for $30 \mathrm{~min}$ (Molecular Probes, Invitrogen, Carlsbad; $10 \mu \mathrm{g} / \mathrm{mL}$ ) or MAb35 (Iowa Hybridoma bank). Images were obtained with a Zeiss confocal microscope and processed with ImageJ, Adobe Photoshop and Adobe Illustrator. Optical cross section was obtained off line by cropping a $30-\mu \mathrm{m}$ section of the $\mathrm{z}$ stacks at the proper somite angle and projecting these stacks $90^{\circ}$ using Leica software or ImageJ (NIH).

\section{Mosaic Analysis by Transplantation}

Transplantation experiments were done as described in a recent review of mosaic analyses in zebrafish (CarmanyRampey and Moens, 2006). Muscle mosaic analysis: cells from the early blastomere stage actin-GFP transgenic embryos (3 hpf) were removed and transferred into unlabeled age matched ennui embryos. The effect of transplanting wild-type muscle cells in ennui mutants on AChR clusters was assayed with the particle analysis plugin for ImageJ (NIH). The area immediately adjacent to the somitic boundary $(10 \mu \mathrm{m})$ was not included in the clustering 
calculation because of the pronounced relocalization of $\mathrm{AChR}$ seen in the mutants. Motoneuron mosaic analysis: cells were removed from a $3 \mathrm{~h}$ transgenic HB9-mGFP embryo and transplanted either into age matched ennui mutant or wild-type embryos. The number of transplanted cells was purposely kept low in each host to minimize effects from non-motoneuron cell types that could potentially be transplanted but not visualized with GFP. In some cases the GFP signal was enhanced with anti-GFP antibody (Torrey Pines, Houston; 1:5000).

\section{Exogenous Agrin Application}

In vivo: as described earlier for physiological assays, embryos were anesthetized, pinned and the skin overlying somites two through 12 was removed on one side at $36 \mathrm{~h}$ of development and embryos were exposed to bath applied recombinant rat agrin (R\&D systems, Minneapolis, $160 \mathrm{ng} /$ $\mathrm{mL}$ in extracellular recording solution) for $10 \mathrm{~h}$. Embryos were then fixed, stained with BTX and the superficial muscle layer was imaged on a Zeiss confocal microscope, processed with ImageJ, Photoshop and Illustrator. In vitro: modified from the zebrafish book (Westerfield, 2000). Briefly, 2-day-old embryos were dissociated in custom ATV solution (in $\mathrm{mM}$ ): $137 \mathrm{NaCl}$ 137, $5 \mathrm{KCl}, 1$ EDTA, 7 $\mathrm{NaCO}_{3}, 6,0.25 \%$ trypsin, $\mathrm{pH}$ 7.8. The dissociated cells were grown in charged Petri dishes (Falcon, primeria) for $24 \mathrm{~h}$ in the dark at room temp in an L15 based media supplemented with $5 \%$ horse serum and $50 \mathrm{U} / \mathrm{mL}$ penicillin, $0.05 \mathrm{mg} / \mathrm{mL}$ streptomycin. Agrin $200 \mathrm{ng} / \mathrm{mL}$ was added to the cultured muscle cells and these were allowed to grow for $6 \mathrm{~h}$ in the presence of agrin. The cultures were fixed with $4 \%$ paraformaldehyde and stained as described earlier for AChR using $\alpha$-BTX.

\section{RESULTS}

\section{ennui Mutants Transiently Swim More Slowly Due to Weaker Muscle Contractions}

The ennui mutation was identified from an ENU mutagenesis screen for behavioral defects. The mutation was inherited as an autosomal, recessive trait. Video analysis of freely behaving embryos revealed that ennui mutants showed no measurable deficit in motor behavior until swimming starts after $28 \mathrm{hpf}$ (not shown). After $28 \mathrm{hpf}$ there was a dramatic reduction in swimming speed in mutants. This motor deficit peaked at $36 \mathrm{hpf}$ with ennui embryos swimming at less than $18 \%$ of the speed of wild-type sibling embryos [Fig. 1(A,B); mutant: $3.2 \pm 0.3 \mathrm{~mm} / \mathrm{s}$, $n=15 \mathrm{v} / \mathrm{s}$ wtsib:16.3 $\pm 1.1 \mathrm{~mm} / \mathrm{s}, n=15 ; p<0.01]$. By 48 hpf ennui mutants recovered to $52 \%$ of wildtype swimming speed [Fig. 1(A,B); mutant: $14.0 \pm$ $1.1 \mathrm{~mm} / \mathrm{s}, n=10 \mathrm{v} / \mathrm{s}$ wtsib: $27.3 \pm 1.7 \mathrm{~mm} / \mathrm{s}, n=10$;
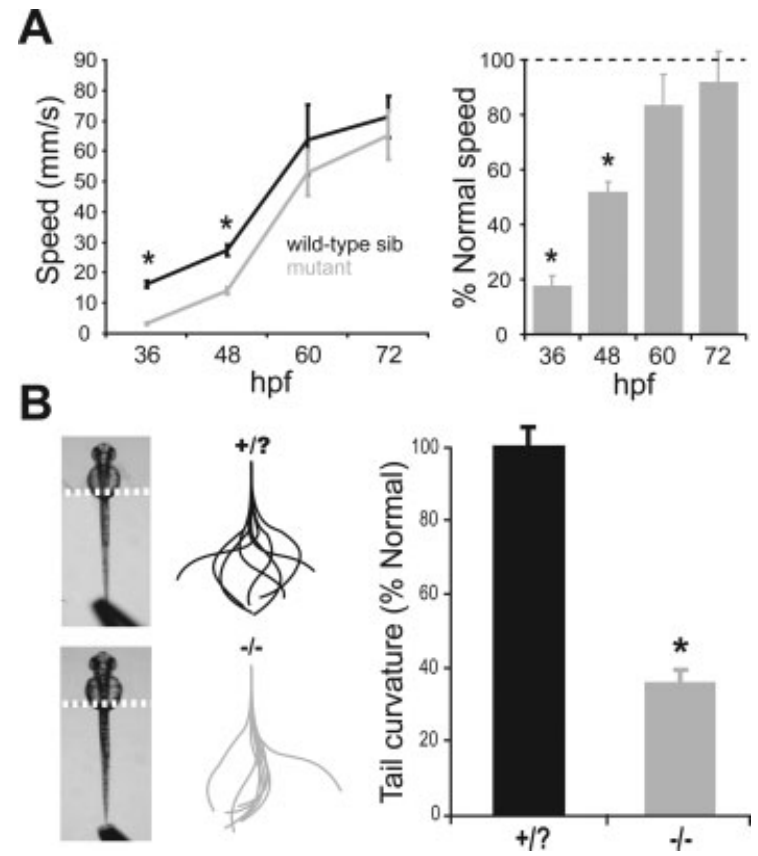

Figure 1 ennui embryos swim more slowly. A: Graph (left) and histogram (right) showing that mutants swim more slowly following tactile stimulation than wild-type sibs at 36 and 48 hpf but not at later stages. B: Left, micrograph of embryos with their heads and yolk sacks embedded in agarose (boundary noted by dashed line) leaving the trunks and tails free. Forceps used to stimulate embryos can be seen at the bottom. Middle, tracings of the trunk and tail of wild-type sibs (top) and mutants (bottom) when bending was greatest during a swimming episode for eight different embryos. Right, histogram of average tail curvature during swimming episodes ( $n=8$ embryos each, see Methods for details) showing that mutants do not swim as vigorously as wild-type sibs. Note: In this and other figures the asterisk denotes $p<0.05$, Student's $t$-test.

$p<0.01]$ and by $72 \mathrm{hpf}$ their swimming speed was comparable to that of wild-type sibs [Fig. 1(A,B); mutant: $65.2 \pm 8.1 \mathrm{~mm} / \mathrm{s}, n=10 \mathrm{v} / \mathrm{s}$ wtsib: $71.2 \pm 6.9$ $\mathrm{mm} / \mathrm{s}, n=10, p=0.37]$. The average duration of swimming episodes, however, was not significantly different in ennui homozygotes at $36 \mathrm{hpf}(4.2 \pm 1.0 \mathrm{~s}$ for ennui $\mathrm{v} / \mathrm{s} 4.4 \pm 0.5 \mathrm{~s}$ for wild-type sibling embryos, $n=8, p=0.9$ ). Furthermore, mutant embryos and larvae viewed with DIC optics showed no obvious defects in general body morphology, patterning of the CNS or muscle cell morphology (not shown). Mutants exhibited no increase in cell death, were viable and fertile (not shown).

One explanation for this reduction in swimming performance was that ennui embryos have weaker muscle contractions and thus smaller movements of the trunk and tail during swimming. To measure swimming movements, the heads of embryos were 
restrained in agarose whereas their trunks and tails were free to move in response to tactile stimuli [Fig. 1(C)]. A quantitative analysis of the trunk and tail curvature (excursion of the trunk and tail) during swimming (see Methods) revealed that the trunk and tails of ennui embryos ( $36 \mathrm{hpf}$ ) exhibited (35 \pm 4$) \%$ of the deformation seen in wild-type embryos $[n=8$ embryos, Fig. 1(C)]. This pronounced decrease in the bending of the trunk and tail of mutants could either result from weaker contractile properties of the muscle fibers, decreased excitation-contraction (e-c) coupling, or decreased synaptic drive at the NMJ.

To test for a deficit in the contractile properties or e-c coupling of ennui muscles, the strength of muscle contraction was measured in response to membrane depolarization. A transient depolarization of muscles was induced by ejecting a small volume of $\mathrm{KCl}(150$ $\mathrm{m} M$ ) from a pipette onto an exposed axial myotome (as described in Methods) and the resulting contraction estimated by measuring the reduction in length of the myotome as a percentage of the relaxed length. Wild-type siblings showed a $(20 \pm 2) \%$ reduction in length whereas ennui embryos showed a comparable $(19 \pm 2) \%$ reduction in length at maximal contraction (not shown, $p=0.53, n=4$ ). These analyses suggest that e-c coupling and the contractile machinery of ennui muscles are unperturbed but synaptic drive at the $\mathrm{NMJ}$ is defective.

\section{The CNS Generates Normal Swimming Output in ennui Mutants}

Two hypotheses can explain a weaker synaptic drive to the muscle cells in mutants. The swimming output from the motoneurons and/or the NMJ might be defective in ennui embryos. To see if a weaker motor drive from the CNS was responsible for the weaker contractions in mutants, the electrophysiological properties and activity of motoneurons during swimming were examined by voltage recordings. Animals were paralyzed with curare while recording the activity of motoneurons during fictive swimming. At 36 hpf when the mutant phenotype was most severe, the resting potential (wtsib: $-56 \pm 3 \mathrm{mV}, n=4 \mathrm{vs}$. ennui: $-55 \pm 4 \mathrm{mV}, n=4 ; p>0.3)$ and input resistance (wtsib: $586 \pm 41 \mathrm{M} \Omega, n=4$ vs. ennui: $522 \pm$ $36 \mathrm{M} \Omega, n=4 ; p>0.3$ ) of primary motoneurons were comparable between wild-type siblings and ennui mutants. Furthermore, the activity of motoneurons during swimming was normal in mutants. Swimming can be initiated by tactile stimulation of the head or trunk while recording from motoneurons. In ennui mutants $(n=7)$ tactile stimulation induced a long

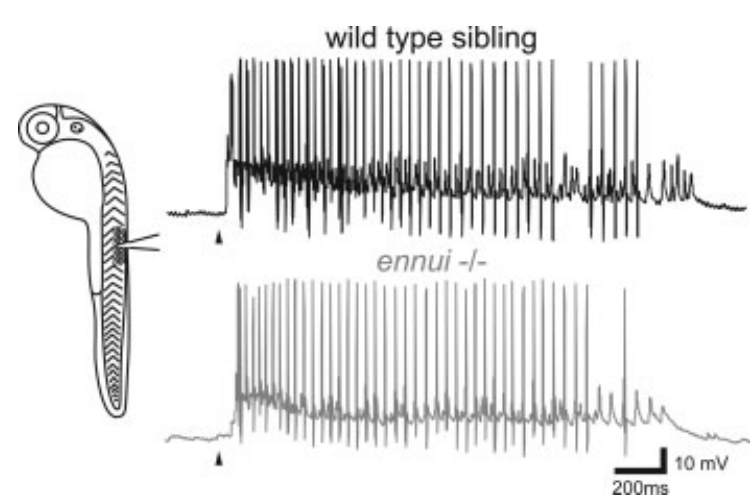

Figure 2 Swimming neural circuits are activated normally in ennui embryos. Left, drawing of $36 \mathrm{hpf}$ embryos depicting how motoneuron recordings are made. Right, voltage recordings from primary motoneurons in homozygous mutant and wild-type siblings showing that tactile stimulation (arrowhead) initiates comparable trains of action potentials in motoneurons that represent fictive swimming from a wild-type sib and ennui mutant.

train of action potentials during a fictive swimming episode that was not different from that observed in wild-type siblings $(n=5)$ (see Fig. 2). The frequency of action potentials was comparable between mutant and wild-type siblings (wt: $21 \pm 1 \mathrm{~Hz}$; ennui: $22 \pm 1$ $\mathrm{Hz} ; n=7,5 ; p=0.47$ ) as was the distribution of interspike intervals (not shown). The normal activity of motoneurons during fictive swimming when combined with normal e-c coupling and contractile properties of muscles in ennui mutants strongly suggests that the defect resides at the NMJ.

\section{Synaptic Transmission at the NMJ Is Weaker in ennui Mutants}

To see if synaptic transmission at the NMJ was weaker in ennui embryos, the synaptic activity during fictive swimming was recorded following tactile stimulation of embryos at $36 \mathrm{hpf}$. Tactile stimulation induced a train of rhythmic endplate depolarizations that represented fictive swimming [Fig. 3(A)]. As expected from motoneuron recordings, the duration of the train of rhythmic depolarizations and the frequency of the depolarizations were comparable between mutant and wild-type sibling muscles [Fig. 3(B), wtsib: $1270 \pm$ $370 \mathrm{~ms}, 19 \pm 1 \mathrm{~Hz}, n=7$ vs. ennui: $1610 \pm 380 \mathrm{~ms}$, $20 \pm 2 \mathrm{~Hz}, n=7 ; p>0.5$ ]. However, the amplitude of tactile evoked synaptic potentials was significantly reduced in ennui embryos compared with wild-type sibs (wtsib: $4.9 \pm 0.7 \mathrm{mV}, n=4$ vs. ennui: $1.8 \pm 0.5$ $\mathrm{mV}, n=4 ; p<0.01)$. The reduction in endplate potentials likely resulted from a decrease in synaptic currents as the input resistance of muscle fibers was not 


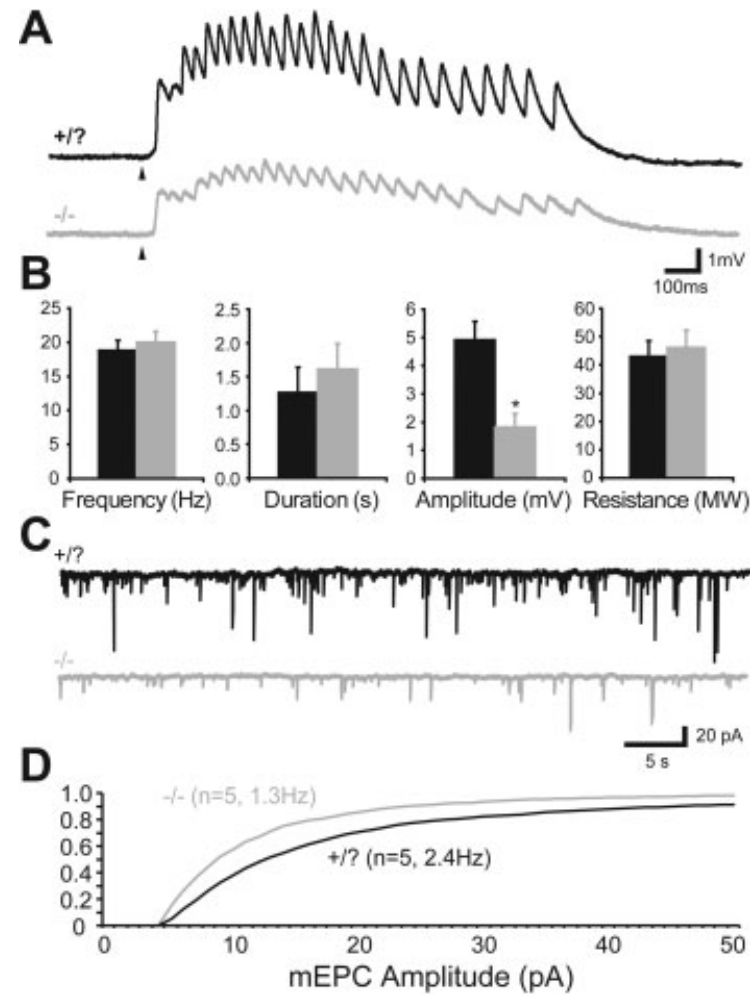

Figure 3 Touch evoked synaptic potentials and spontaneous miniature currents are weaker at the NMJ in ennui embryos. A: Voltage recordings from muscle fibers showing that tactile stimulation (arrowheads) induces rhythmic depolarizations that are smaller in amplitude in mutants compared with wild-type sibs. B: Histograms demonstrating that the frequency of the muscle depolarizations, duration of the train of depolarizations, and input resistance of muscle fibers are comparable between wild-type sibs and mutants, but the amplitude of the rhythmic depolarizations is significantly smaller ( $n=4$ embryos each). C: Voltage clamp recordings of spontaneous miniature synaptic currents in muscles showing that the amplitude and frequency of these currents are decreased in mutants. D: A cumulative histogram of the amplitude of mEPCs, in which the faster rising curve for mutants highlights the smaller amplitude of their NMJ currents. Note that the wild type curve has not reached 1.0 by the end of the graph. This points to a population of events larger than $50 \mathrm{pA}$ in the wild type embryos that is not present in the mutants. The frequency, shown here as a reference, was calculated by dividing the total number of events by the duration of the recordings ( $n=5$ each).

significantly different between ennui and wild-type sibling embryos [Fig. 3(B); wtsib: $43 \pm 5 \mathrm{M} \Omega, n=4$ vs. ennui: $46 \pm 6 \mathrm{M} \Omega, n=4 ; p=0.72]$. At $3 \mathrm{dpf}$ evoked responses in ennui muscle were indistinguishable from control (not shown) corresponding with near normal swimming by mutants at this time. Thus, it appears that the weaker swimming at embryonic stages may be due to a defect at the NMJ.
To further analyze the NMJ in ennui embryos, spontaneous miniature endplate currents (mEPC) were analyzed at $36 \mathrm{hpf}$. The frequency (wtsib: 2.4 $\mathrm{Hz}, n=5$ vs. ennui: $1.3 \mathrm{~Hz}, n=5 ; p<0.001)$ and amplitude (wtsib: $20.0 \pm 0.4 \mathrm{pA}, n=5$ vs. ennui: $11.3 \pm 0.3 \mathrm{pA}, n=5 ; p<0.001$ ) of mEPCs were both significantly reduced in ennui embryos [Fig. $3(\mathrm{C}, \mathrm{D})]$. The reduction in the frequency of events could result from a smaller number of synapses or could be caused by fewer events reaching the detection threshold because of their lower average amplitude. However, the reduction in mEPC amplitude observed along with the decrease in touch evoked endplate currents clearly demonstrate a decreased efficiency of synaptic transmission at the NMJ.

\section{AChRs Are Mislocalized in ennui Muscles}

A decrease in nicotinic AChRs at the NMJ could account for weaker synaptic transmission at the NMJ. To examine this, AChR localization was assayed by labeling with BTX and motor axons with anti-SV2. In the most caudal myotomes at $24 \mathrm{hpf}$ motor axons have not yet projected out of the spinal cord yet these muscles in both wild-type embryos and mutant embryos contained AChR clusters in the midregion of the muscle fibers [Fig. 4(A,B)]. Similarly, at $18 \mathrm{hpf}$ when motor axons first exited the spinal cord in the more rostral segments prepatterned clusters were unperturbed in trunk segments in both mutants and wild-type embryos (not shown). Thus nerve-independent clusters of AChRs were unaffected by the ennui mutation.

In more rostral myotomes at $24 \mathrm{hpf}$, motor axons have extended into the myotomes and AChR clusters overlapped extensively with motor terminals in wildtype but not mutant embryos [Fig. 4(C,D)]. Thus, there was a decrease in synaptic clustering of AChRs in mutant muscles at $24 \mathrm{hpf}$. AChR clusters were absent from muscle fibers in ennui embryos except for a few fibers located at the horizontal myoseptum that were likely to be muscle pioneers [Fig. 4(D)]. In addition to decreased synaptic AChR clusters in mutant muscles, there was an increase in AChRs at the boundaries of the myotomes [Fig. 4(C,D)]. At 36 hpf, a time that was coincident with the most severe behavioral phenotype, the clustering defect was clearly seen along the motor axon path [Fig. 4(E,F)]. AChRs were also enriched significantly at the myotome boundaries at $36 \mathrm{hpf}$ in ennui mutants as they are at 24 hpf [Fig. 4(E,F)]. Thus weaker synaptic transmission at the NMJ of ennui embryos is likely due to a lack of proper AChR clustering.

The distribution of AChRs was still aberrant at $72 \mathrm{hpf}$ despite the fact that by this time mutants 

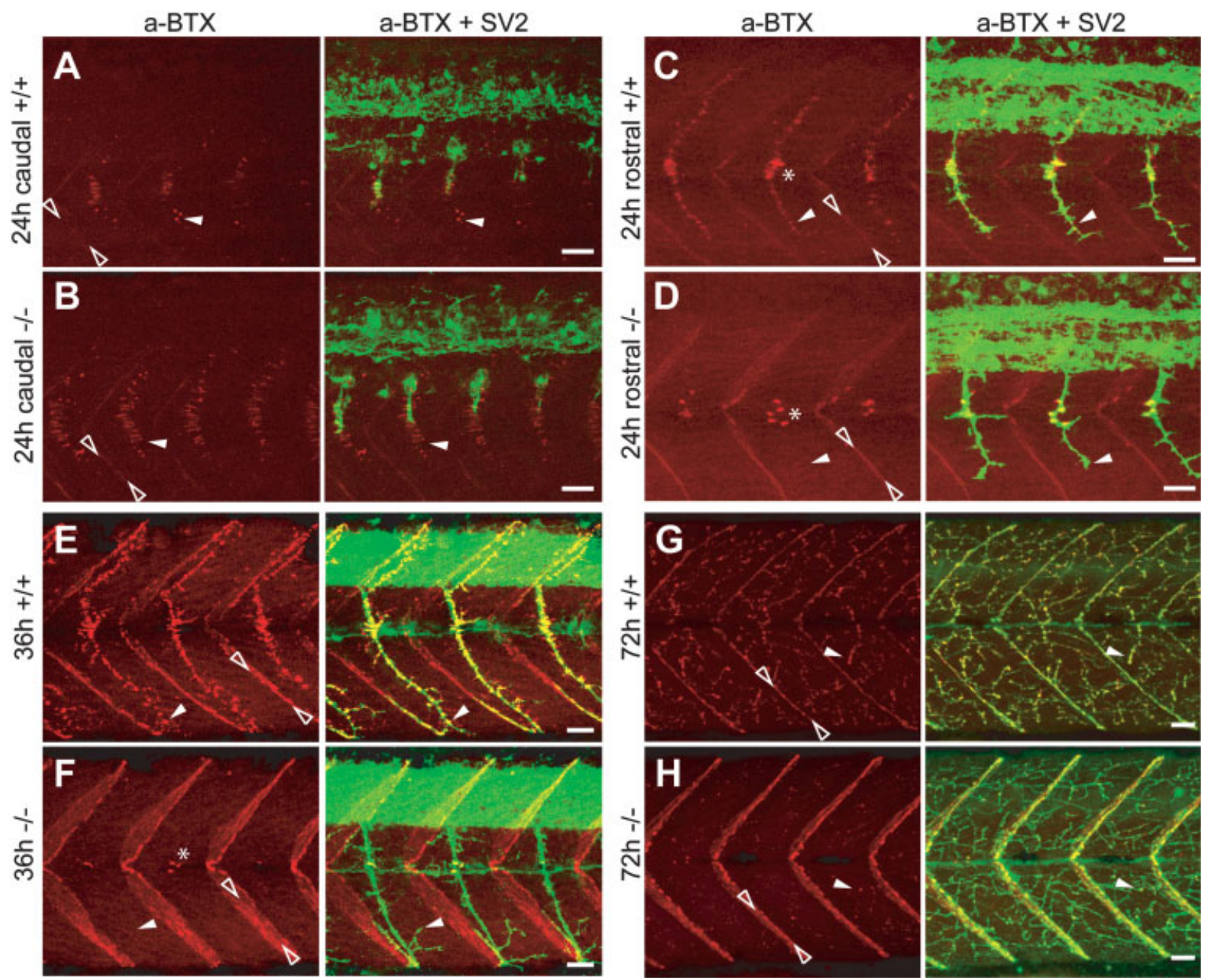

Figure 4 Aneural AChR clusters are normal, whereas synaptic AChR clusters are reduced and ectopic AChRs are aggregated at the myotomal borders in ennui embryos. Sideviews of axial myotomes with motor axons labeled with anti-SV2 (green) and AChRs with BTX (red) in all panels. Anterior is left and dorsal up. A-B: The caudal (immature) myotomes of embryos at $24 \mathrm{hpf}$ exhibit prepatterned AChR clusters in both mutant and wild-type embryos (arrowheads). C-D: Clustering of AChR along motor axons is reduced in more mature rostral segments of 24 hpf mutant embryos compared with wild-type embryos (white arrowheads). The asterisk denotes AChR clusters at the horizontal myoseptum likely on muscle pioneers in wild-type embryos and mutants. E-F: AChR clusters are coextensive with motor axons in wild-type embryos but absent along motor axons in mutants at 36 hpf (white arrowheads). AChRs appear to be more extensively expressed at the myotomal boundary (open arrowheads) in mutants. G-H: AChR clusters are distributed throughout the somite (white arrowhead) and colocalize with motor branches in wild-types, whereas there are few clusters in mutants at $72 \mathrm{hpf}$. AChRs at the myotomal borders (open arrowheads) are increased in mutants compared with wild-type embryos. Scale bar is $25 \mu \mathrm{m}$. [Color figure can be viewed in the online issue, which is available at www.interscience.wiley.com.]

exhibited considerable behavioral recovery [Fig. $4(\mathrm{G}, \mathrm{H})]$. Decreases in AChR clustering were seen along the axon path at $72 \mathrm{hpf}$ as well as increases in AChRs at the myotome boundary [Fig. 4(G,H)]. Thus, mutants exhibited functional recovery despite aberrant distribution of AChRs.

\section{The ennui Gene Is Required by Muscles for the Formation of Synaptic AChR Clusters}

The mislocalization of AChRs in mutants could arise from a defect in motoneurons, muscles or both. To 
test for the locus of ennui function, we performed genetic mosaic analysis by transplanting cells of one genotype into a host of another genotype. Donor embryos were either wild-type transgenics expressing GFP under the control of the $\alpha$-actin promoter (Higashijima et al., 1997) or wild-type embryos injected with FITC-dextran at the 1 cell stage. Wild-type cells ( $n=7$ ) labeled by the $\alpha$-actin promoter transplanted to ennui hosts that developed into muscles showed large AChR clusters by 48-60 hpf whereas the host, mutant muscles surrounding the transplant did not show such clusters (Fig. 5). The number and size of AChR clusters were assayed for wild-type to mutant mosaics $(n=7)$. Wild-type muscle cells transplanted into mutant hosts accounted for less than $15 \%$ of the area sampled, yet they gave rise to $76 \%$ of all AChR clusters observed (256/334). The clusters on to wild-type muscle cells were also $240 \%$ larger on average than the clusters on mutant cells (wt: $6.9 \mu \mathrm{m}^{2}$; mut: $2.8 \mu \mathrm{m}^{2}$ ). In transplants involving FITC-labeled wild-type donor cells, the wild-type muscles with large AChR clusters were innervated by unlabeled, mutant motoneurons, and no other cell type such as glia were present in the myotome, thus ruling out the possible involvement of wild-type motoneurons or non-muscle myotomal cells ( $n=5$, not shown). Mutant muscle cells transplanted in wild-type hosts exhibited decreased clustering compared with the host, wild-type muscles ( $n=6$, not shown). Furthermore, transplantation of wild-type motoneurons into

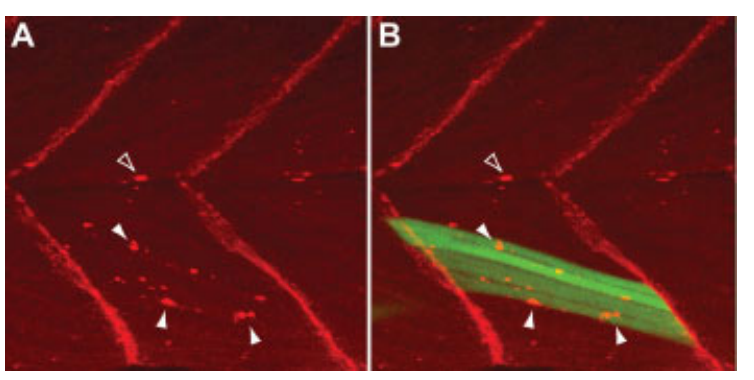

Figure 5 The ennui gene product is required cell-autonomously in muscle for normal clustering of AChRs. Sideviews of myotomes with muscle fibers derived from wildtype, -actin: gfp transgenic cells transplanted into a nontrangenic, ennui host fixed at $48 \mathrm{hpf}$ and labeled with BTX for AChRs (red). A: Some of the muscle fibers exhibit large clusters of AChRs (white arrowheads) whereas most of the fibers do not. Muscle pioneers exhibit AChR clusters (open arrowhead). B: Same myotomes showing that the fibers (green) exhibiting AChR clusters (white arrowheads) are donor derived wild-type fibers. Mutant muscle pioneers also exhibit AChR clusters (open arrowhead). [Color figure can be viewed in the online issue, which is available at www.interscience.wiley.com.] mutant hosts did not rescue normal clustering (see Fig. 7). These results suggest that the ennui gene acts cell autonomously in muscles and likely encodes for a muscle factor that is required for the development of AChRs at the NMJ.

Two muscle factors required for proper synaptic localization of AChRs are MuSK and rapsyn (Kummer et al., 2006). Since there are zebrafish mutations in MuSK/unplugged (Zhang et al., 2004) and rapsyn/twitch once (Ono et al., 2002), we examined whether the ennui mutation might genetically complement MuSK/unplugged or rapsyn/twitch once. Crosses of ennui homozygotes and MuSK/unplugged carriers or rapsyn/twitch once carriers did not generate any progeny with mutant behavior demonstrating that the ennui phenotype is not due to mutations in genes encoding either MuSK or rapsyn. In support of the complementation data, we meiotically mapped ennui to linkage group 7 (LG7), which is different from the published locations of MuSK (LG10) (Zhang et al., 2004) and rapsyn (LG18) (Ono et al., 2002). The location of ennui on LG7 excluded two other genes that may regulate AChRs, dystroglycan-1 (Parsons et al., 2002) and $\delta$-sarcoglycan (Guyon et al., 2005), that have been meiotically mapped to LG22 and LG21, respectively, in zebrafish. Furthermore, we ruled out many other genes known or suspected to be important for the formation of the NMJ by physically mapping them with the LN54 radiation hybrid panel (Hukriede et al., 1999) (Table 1). These results showed that ennui is not one of the many genes implicated in the formation of the NMJ.

\section{AChRs Are Aberrantly Localized to the Myotomal Boundaries in Larval Fast-Twitch ennui Muscles}

There is an increase in AChRs at the myotomal boundaries in ennui mutants. Since the myotomes consist of superficial, slow-twitch and deep, fast-twitch muscles, we examined the distribution of AChRs in the two sets of muscles with confocal microscopy. At 96 hpf wild type larvae exhibited AChRs along the myotomal boundaries in the most-lateral $12 \mu \mathrm{m}$ of the myotome corresponding to the slow-twitch muscles but not in more medial myotome corresponding to the fast-twitch muscles [Fig. 6(Ai,Aii)]. Thus, by $96 \mathrm{hpf}$, AChRs aggregate at the myotomal boundaries in slow-twitch muscles but not fast-twitch muscles. In mutant larvae, however, there was an increase in AChRs at the myotomal boundaries in the deeper layers of the myotome compared with wild type [Fig. 6(Aiii), iv; $n=6$ for both mutant and wildtype]. 
Table 1 Physical Mapping of Candidate Genes

\begin{tabular}{|c|c|c|c|}
\hline Gene & Linkage Group & LOD & Reference \\
\hline Abelson murine leukemia viral oncogene homolog 1 (ABL-1) & 8 & 10.1 & Finn et al., 2003 \\
\hline Abelson murine leukemia viral oncogene homolog 2 (ABL-2) & 5 & 19.3 & Finn et al., 2003 \\
\hline Acetylcholinesterase (ACHE) & $7(>60 \mathrm{cM})$ & 13.3 & Downes and Granato, 2004 \\
\hline Adenomatosis polyposis coli-1 (APC-1) & 10 & $9.4^{\mathrm{a}}$ & Wang et al., 2003 \\
\hline Adenomatosis polyposis coli-2 (APC-2) & 11 & $9.0^{\mathrm{a}}$ & Wang et al., 2003 \\
\hline Agrin (AGRIN) & 23 & 14.1 & Burgess et al., 1999 \\
\hline Biglycan-1 (BSPG1) & 8 & 10.4 & Bowe et al., 2000 \\
\hline Biglycan-1 (BSPG1) & 23 & 13.4 & Bowe et al., 2000 \\
\hline Biglycan-2 (BSPG2) & 4 & 18.5 & Bowe et al., 2000 \\
\hline CDC42 binding protein kinase $\beta$ (CDC42BPB; DMPK-like) & 20 & 19.3 & Weston et al., 2000 \\
\hline CDC42 binding protein kinase $\gamma(\mathrm{CDC} 42 \mathrm{BPG})$ & 17 & 14.7 & Weston et al., 2000 \\
\hline Chondroitin sulphate proteoglycan 2 (CSPG-2) & 10 & 9.7 & Mook-Jung and Gordon, 1995 \\
\hline Chondroitin sulphate proteoglycan 4 (CSPG-4) & 10 & 14.9 & Mook-Jung and Gordon, 1995 \\
\hline Chondroitin sulphate proteoglycan 6 (CSPG-6) & 22 & 16.2 & Mook-Jung and Gordon, 1995 \\
\hline Discs large homolog-associated protein 1 (DLGAP-1) & 2 & 19.3 & Chen and Featherstone, 2005 \\
\hline Discs large homolog-associated protein 2 (DLGAP-2) & 20 & 6.2 & Chen and Featherstone, 2005 \\
\hline Dishevelled-2 (DVL-2) & $7(>55 \mathrm{cM})$ & 13.9 & Luo et al., 2002 \\
\hline Erythroblastic leukemia viral oncogene homolog 2 (ErbB2) & 12 & 15.9 & Lacazette et al., 2003 \\
\hline Erythroblastic leukemia viral oncogene homolog 3 (ErbB3) & 23 & 18.8 & Lacazette et al., 2003 \\
\hline Erythroblastic leukemia viral oncogene homolog 4 (ErbB4) & 1 & 13.5 & Lacazette et al., 2003 \\
\hline Geranylgeranyl transferase 1 (GGT) & 14 & 17.9 & Luo et al., 2003 \\
\hline Membrane associated guanylate kinase 1 (MAGI-1) & 8 & 13.7 & Strochlic et al., 2001 \\
\hline Membrane associated guanylate kinase 1 (MAGI-1) & 11 & 11.7 & Strochlic et al., 2001 \\
\hline Membrane associated guanylate kinase 2 (MAGI-2) & 25 & 12.2 & Strochlic et al., 2001 \\
\hline Membrane associated guanylate kinase 3 (MAGI-3) & 23 & 11.7 & Strochlic et al., 2001 \\
\hline Neuregulin 1 (NRG-1) & 10 & 10.1 & Rimer, 2007 \\
\hline Neuregulin 2 (NRG-2) & 5 & $11.6^{\mathrm{a}}$ & Rimer, 2007 \\
\hline Neuronal nitric oxide synthase (nNOS) & 6 & 18.7 & Godfrey and Schwarte, 2003 \\
\hline Neuropilin and tolloid-like protein (NETO-1) & 24 & 13.1 & Gally et al., 2004 \\
\hline Neuropilin and tolloid-like protein 1 (NETO-1) & 2 & 13.8 & Gally et al., 2004 \\
\hline Neuropilin and tolloid-like protein 2 (NETO-2) & 18 & 16.2 & Gally et al., 2004 \\
\hline Nicotinic acetylcholine receptor $\beta 1$ (nAChRb1) & $7(>30 \mathrm{cM})$ & 16.2 & Wallace et al., 1991 \\
\hline Receptor tyrosine kinase-like orphan receptor 1 (ROR-1) & 6 & 14.4 & Francis et al., 2005 \\
\hline Receptor tyrosine kinase-like orphan receptor 1 like (ROR-1 like) & 5 & 15.4 & Francis et al., 2005 \\
\hline Receptor tyrosine kinase-like orphan receptor 2 (ROR-2) & 10 & 13.8 & Francis et al., 2005 \\
\hline Utrophin (UTRN) & 23 & 10.2 & Banks et al., 2003 \\
\hline Yes kinase (YES) & 2 & 15.5 & Sadasivam et al., 2005 \\
\hline
\end{tabular}

The chromosomal assignment is given as a linkage group and the LOD score for each location to indicate the reliability of mapping.

${ }^{a}$ A second linkage was within 3 LOD scores of the first (although not LG7) producing some ambiguity in the location. For genes located on LG7 additional information was given as to the distance in centimorgans (cM) from the critical region of ennui.

If AChRs are concentrated at the myotomal boundaries in all muscle layers in the mutants, then one should be able to visualize this in a transverse section along the boundary. To take a closer look at the boundaries we obtained thin optical confocal sections of the region containing the myotomal boundaries [Fig. 6(Bi), see Methods]. In wild-type larvae, these sections revealed a high density of receptors at the myotomal boundary in the most lateral part of the myotome whereas the medial myotome exhibited a lower density of AChRs [Fig. 6(Bii)]. In mutants, there was a high density of AChRs at the myotomal boundary throughout the myotome both laterally and medially [Fig. 6(Biii); $n=3$ for both mutant and wild-type]. Thus the optical sections along the myotomal boundaries confirmed the lateral confocal images and demonstrated that AChRs accumulate at the boundaries in fast-twitch muscles in mutant larvae but not wild-type larvae.

\section{ennui Larvae Exhibit Increased Branching by Motor Axons at Myotomal Boundaries}

The finding that early prepatterned AChRs appear to direct the extension of motor growth cones in zebrafish (Flanagan-Steet et al., 2005; Panzer et al., 2006) 
suggests the possibility that the mislocalized AChRs at the myotome borders of mutant fast twitch muscles might direct motor axons to extend to and branch within this region. To examine this possibility motor axons were labeled with anti-SV2 in $4 \mathrm{dpf}$ larvae and examined with confocal microscopy to delineate motor branching within myotomes. There was extensive branching by motor axons within the border regions of fast twitch muscles in ennui larvae. Confocal images of lateral (superficial) muscles representing the slow twitch muscles showed that motor axons branched at the myotomal boundaries in both wildtype and mutant larvae [Fig. 6(Ci,Cii)]. Similar images of medial (deep) muscles representing fast twitch muscles, however, showed that while there were few motor branches at the myotome borders in wild-type larvae, there were many branches at the
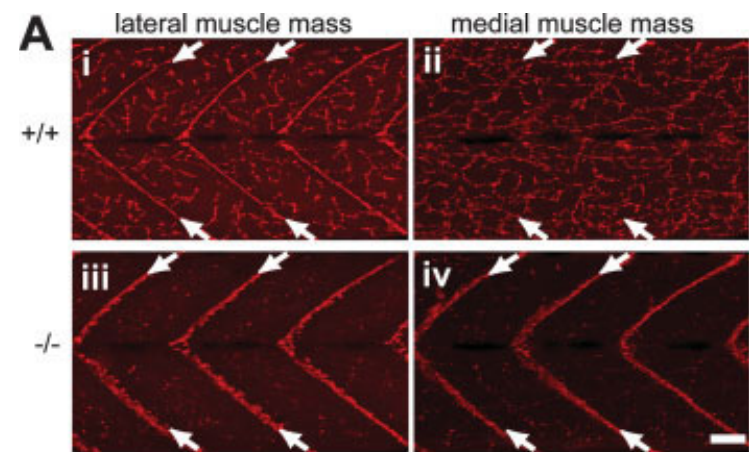

B
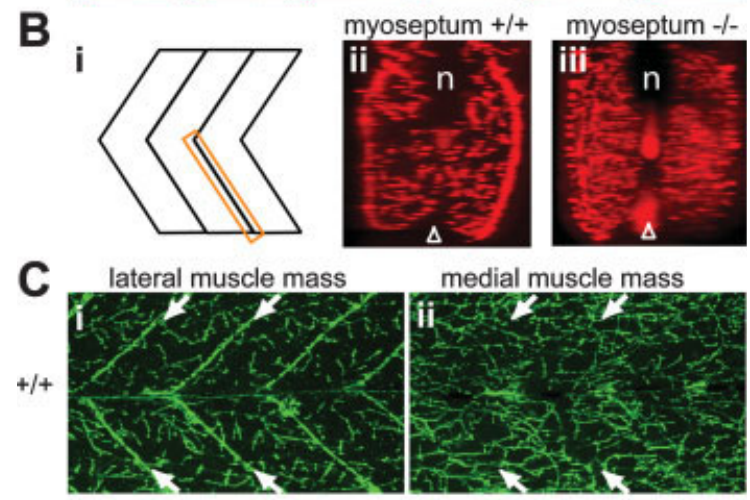

medial muscle mass
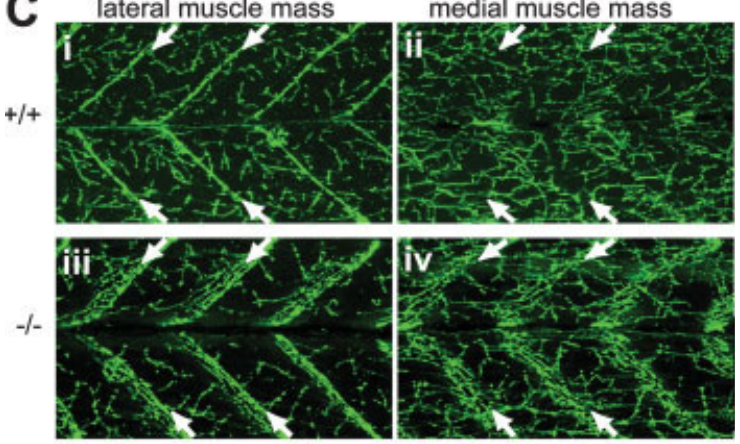

D

myoseptum +/+ myoseptum -/-
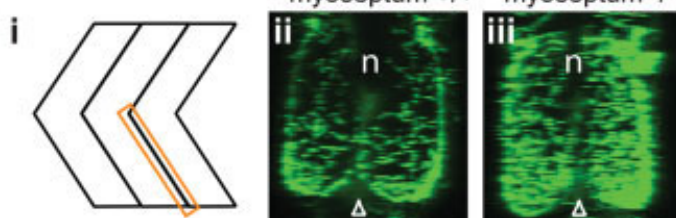

borders in mutants [Fig. 6(Ciii,Civ); $n=5$ for both mutant and wild-type].

Optical sections running along the myotomal segment boundary of the ventral portion of the chevron

Figure 6 AChRs and motor axon branching are increased at the myotomal borders in ennui larvae. Confocal sideviews of myotomes labeled with BTX (red) for AChRs and anti-SV2 (green) for motor axons at $96 \mathrm{hpf}$. Ai: Lateral myotome in a wild-type larva exhibits AChR clusters throughout the slow-twitch muscles including at the myotomal boundaries (white arrows). Aii: Medial myotome in a wild-type larva exhibits AChR clusters throughout the fasttwitch muscles, but are not enriched at the myotomal boundaries as they are in slow-twitch muscles. Aiii: Lateral myotome in an ennui mutant exhibits few AChR clusters in the slow-twitch muscles with the exception of an increase in AChRs at the myotomal borders. Aiv: Medial myotome in the ennui mutant exhibits few AChR clusters in fasttwitch muscles with the exception of abundant AChRs at myotomal boundaries. Bi: Diagram showing the plane of the optical section through the ventral myoseptum shown in Bii and Biii. The section is parallel to the myotomal border of the ventral half of the myotome. Bii: Optical section of a wild-type larva showing a high density of AChRs at the superficial surface of the ventral myotome along the myotomal border and scattered AChR clusters in more medial portions of the myotome. $\mathrm{N}$ denotes the notocord and the open arrowhead the midline of the embryo. Biii: Optical section of an ennui larva showing a high density of AChRs throughout the ventral myotome along the myotomal border both at the superficial surface and medial portions. Ci: Lateral myotome in a wild-type larva exhibits motor branches throughout the slow-twitch muscles including along the myotomal boundary regions (white arrows). Cii: Medial myotome in a wild-type larva exhibits motor branches throughout the fast twitch muscles but not along the myotomal boundaries. Ciii: Lateral myotome in an ennui larva exhibit motor branches throughout the slow-twitch muscles and along the myotomal boundaries as in wild-type. Civ: Medial myotome in the ennui larva exhibits an increase in motor branches in fasttwitch muscles along the myotomal boundaries compared with wild-type larvae. Di: Diagram showing the plane of the optical section through the ventral myoseptum shown in Dii and Diii. The section is parallel to the myotomal border of the ventral half of the myotome. Dii: Optical section of a wild-type larva showing a high density of motor branches at the superficial surface of the ventral myotome along the myotomal border and scattered branches in more medial portions of the myotome. $\mathrm{N}$ denotes the notochord and the open arrowhead the midline of the embryo. Diii: Optical section of an ennui larva showing a high density of motor branches throughout the ventral myotome along the myotomal border both at the superficial surface and medial portions. Scale bars, $25 \mu \mathrm{m}$. [Color figure can be viewed in the online issue, which is available at www.interscience.wiley.com.] 


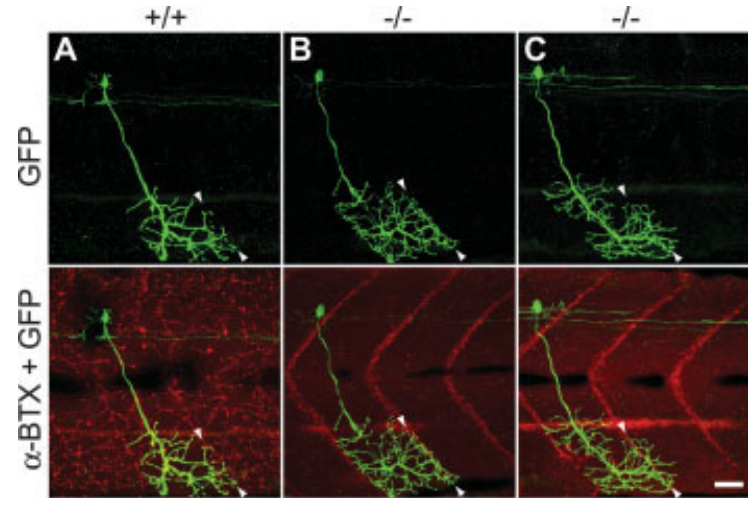

Figure 7 Branching by $\mathrm{CaP}$ motor axons is increased in ennui larvae. Sideviews of $h b 9$ : $m g f p$, wild-type CaP motoneurons (green) transplanted into a nontransgenic, ennui or wild-type host labeled with BTX for AChRs. A: A wildtype $\mathrm{CaP}$ donor motoneuron branches within the ventral myotome of a single segment of a wild-type host. Arrowheads denote the myotomal border. B: A wild-type CaP donor motoneuron exhibits increased branches within the ventral myotome of a single segment of an ennui host. C: A wild-type $\mathrm{CaP}$ donor motoneurons exhibits increased branches that cross the myotomal boundary. In these panels the longitudinal line of red in the ventral myotome is due to autofluorescence by the dorsal aorta. Scale bar, $25 \mu \mathrm{m}$.

shaped myotome corroborated that there was extensive branching by motor axons in the border region of fast-twitch muscles in mutants but not wild-types. Motor axon branches were found at high density along the superficial surface of the myotome and thus the slow-twitch muscles in wild-type larvae with few branches within the deeper fast-twitch muscles [Fig. 6(Dii); $n=5$ ]. However, numerous branches were located both in the superficial, slow-twitch and deep, fast-twitch muscles in mutants [Fig. 6(Diii), $n=5$ ]. Thus motor axons branch much more extensively within the same region of the fast twitch muscles that contain mislocalized AChRs in ennui mutant larvae.

To determine whether the motor axon branching phenotype was cell autonomous or non-autonomous, genetic mosaics were generated and assayed for branching by motor axons at $96 \mathrm{hpf}$. To do this wildtype blastomeres from $h b 9$ : mgfp transgenic zebrafish, in which motoneurons express a farnesylated, membrane associated GFP (Flanagan-Steet et al., 2005) were transplanted into isochronic, nontransgenic wild-type and ennui host embryos. This generated embryos in which some motoneurons were labeled with GFP at later stages. Individual wild-type motoneurons exhibited increased branching in the myotome boundary regions of fast twitch muscles of ennui hosts compared with wild-type hosts [Fig. 7(A,B)]. Furthermore, colabeling with BTX showed that the branches overlapped with the ectopic AChRs on the fast twitch muscles. This was the case both with primary and secondary motoneurons (not shown). In addition, primary motor axons occasionally extended beyond the myotome boundary in ennui hosts [Fig. 7(C); $n=5 / 9]$. In wild-type hosts primary motor axons never crossed the myotome boundaries [Fig. 7(A); $n=5$ ] concordant with earlier findings that primary motor axons were restricted to a single myotome (Westerfield et al., 1986). Thus, the axons of individual motoneurons branched extensively at the site of ectopic AChRs in ennui muscles. The extensive colocalization of axons and AChRs at the myotome boundaries in ennui fast twitch muscle further suggests the formation of ectopic synapses in ennui larvae, which may underlie the functional recovery observed after 3 days. Furthermore, since the motor branching phenotype was exhibited by wildtype motoneurons in mutant but not wild-type hosts, the branching phenotype appears to be cell nonautonomous. This suggests that a primary defect in the muscles causes the motor branching phenotype. These results are consistent with the hypothesis that there are retrograde signals from muscles that regulate axon branching. The exact nature of this cross talk is unclear but may involve activation of AChRs since chronic exposure of mutant embryos to BTX reduced the excessive branching normally observed in 4-day-old ennui larvae ( $n=3$, not shown).

\section{Exogenous z-Agrin Induces AChR Clusters in Wild-type but not ennui Muscles}

The fact that $\mathrm{z}$-agrin can induce AChR clusters in muscles (Ferns et al., 1992) and ennui likely encodes for a muscle factor required for nerve-dependent AChR clusters suggests that the ennui gene product may be necessary for z-agrin induction of AChR clusters. To test if ennui is necessary for $\mathrm{z}$-agrin function, dissociated muscle cells from $36 \mathrm{hpf}$ wild-type or ennui embryos were cultured and examined for $\mathrm{z}$ agrin induction of AChR clusters. Wild-type muscle cells exhibited AChR clusters even without z-agrin but responded to exogenous z-agrin with significant increases in the number of clusters per cell [Fig. $8(\mathrm{~A})$; control fibers: $2.4 \pm 0.5, n=10$; agrin fibers: $4.8 \pm 0.4, n=15 ; p<0.01]$ and the size of clusters (control fibers: $3.6 \pm 0.7 \mu \mathrm{m}^{2}, n=10$; agrin fibers: $\left.6.1 \pm 0.9 \mu \mathrm{m}^{2}, n=15 ; p<0.05\right)$. Cultured ennui 

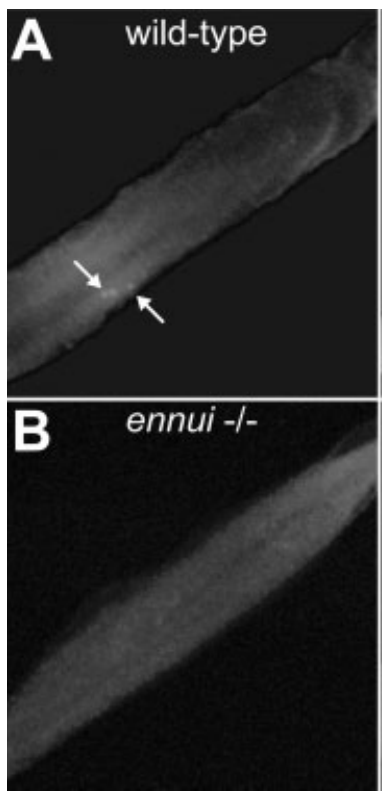
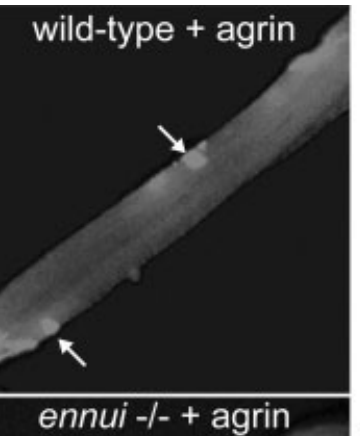
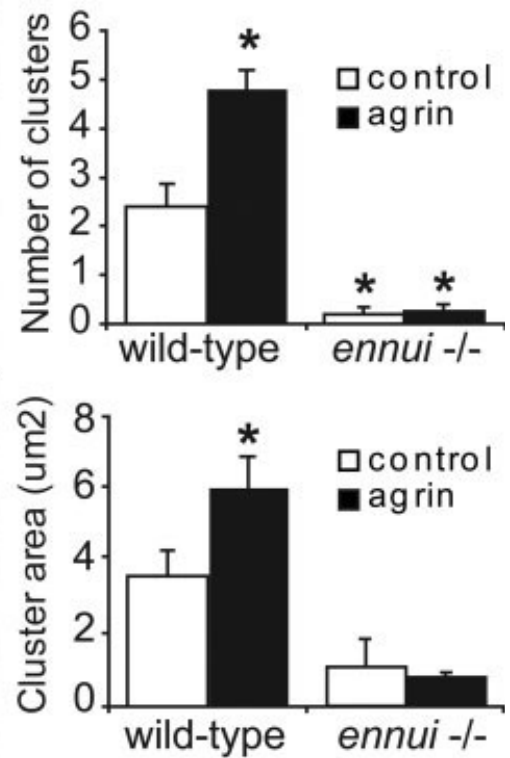

Figure 8 Agrin fails to induce AChR clusters in cultured ennui muscle cells. A: Muscle cells dissociated from wild-type embryos respond to exogenous agrin with a significant increase in the number and size of AChR clusters (arrows). B: Muscle cells from ennui embryos exhibit little to no AChR clusters and exogenous agrin does not induce them. ( $n>9$ for each condition). Scale bar, $10 \mu \mathrm{m}$.

muscle cells, however, exhibited a near complete absence of clusters in the absence of exogenous z-agrin and the number and size of clusters were not increased by the application of z-agrin [Fig. 8(B); number of clusters: control fibers: $0.2 \pm 0.1, n=10$; agrin fibers: $0.2 \pm 0.1, n=9, p>0.9$, size of clusters: control fibers: $1.1 \pm 0.8 \mu \mathrm{m}^{2}, n=10$; agrin fibers: $\left.0.8 \pm 0.2 \mu \mathrm{m}^{2}, n=9 ; p>0.7\right]$. Thus in vitro z-agrin can induce AChR clusters in zebrafish muscles as in muscles of other species and the ennui mutation blocks induction of AChR clusters by z-agrin.

The ability of z-agrin to induce AChR clusters was also tested in vivo by immersing embryos in a z-agrin solution following exposure of the muscles by dissection of the skin overlying the muscles. The superficial layer of muscles overlying somites seven through nine were imaged for quantification. As was found for cultured muscle cells, z-agrin increased the number of AChR clusters by the exposed muscles of wild-type embryos [Fig. 9(A); control fibers: $22 \pm 1$, $n=3$ vs. agrin fibers: $64 \pm 8, n=3 ; p<0.01]$ but not in the muscles of ennui embryos [Fig. 9(B); control fibers: $4 \pm 1, n=3$ vs. agrin fibers: $4 \pm 1, n$ $=3, p>0.6]$. Thus ennui encodes a muscle factor required for $\mathrm{z}$-agrin induction of AChRs clusters and nerve-dependent aggregation of AChRs at the NMJ.

\section{DISCUSSION}

The phenotype of ennui mutants demonstrates that they fail to develop NMJs normally. Embryos homozygous for ennui showed weaker swimming at embryonic stages with recovery at larval stages. The activation of swimming circuits within the CNS, as assayed from motoneuron recordings, appeared normal in ennui embryos while their endplate potentials during fictive swimming and mEPCs were significantly weaker. This reduction in synaptic currents was mirrored by decreases in synaptic AChRs along the motor axon pathway in embryos, whereas prepatterned, aneural AChR clusters and AChR clusters on muscle pioneer cells at the choice point were not affected. Genetic mosaic analysis revealed that synaptic localization of AChRs required ennui cell autonomously in muscle not in motoneurons. Furthermore, application of exogenous agrin found that the ennui gene product is required for agrin-induced aggregation of AChRs. These observations in ennui all point to a defect in the ability of muscle cells to respond to motoneuron derived agrin. Motor axon branching defects were also observed in ennui mutants, especially at later stages, further suggesting that the ennui gene may also be required for retrograde signaling onto the motor axons. 

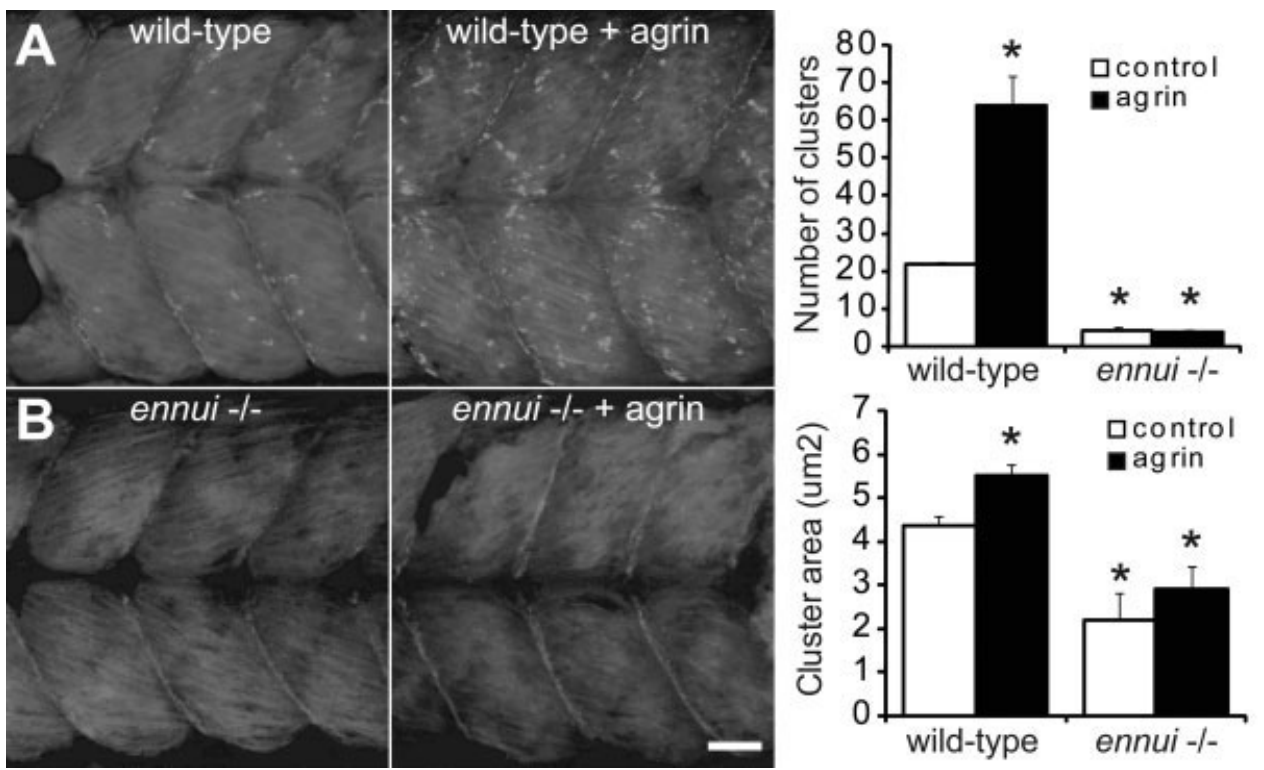

Figure 9 Exogenous agrin does not induce AChR clusters in ennui muscles in vivo. Sideviews of myotomes of $36 \mathrm{hpf}$ embryos with and without exposure to exogenous agrin. Agrin application to skinned myotomal segments induced an increase in the number and size of AChR clusters in three consecutive segments (somite 7-9) of wild-type embryos (A), but not in ennui embryos (B), $(n=3)$. Scale bar is $30 \mu \mathrm{m}$.

\section{ennui Is a Downstream Effector of Agrin}

In mammals the development of the NMJ proceeds with the formation of prepatterned, aneural AChR clusters (Lin et al., 2001) and neural agrin-dependent synaptic aggregation of AChRs (Burgess et al., 1999). Both processes require MuSK(DeChiara et al., 1996), Rapsyn (Gautam et al., 1995), and the recently identified presumptive MuSK interacting proteins DOK-7 and LRP-4 (Lin et al., 2005; Okada et al., 2006; Weatherbee et al., 2006). Similarly, in zebrafish aneural AChR clusters precede the formation of the NMJ (Flanagan-Steet et al., 2005; Panzer et al., 2006) and both are dependent on MuSK (Zhang et al., 2004; Lefebvre et al., 2007). Furthermore, antisense knockdown of zebrafish agrin decreases synaptic AChRs while sparing the aneural clusters of AChRs (Kim et al., 2006) just as in agrin knockout mice and ennui embryos. It has recently been shown that these aneural clusters are short lived in agrin deficient mice and are quickly dispersed by motoneuron activity and release of ACh (Lin et al., 2005; Misgeld et al., 2005). The quick disappearance of aneural clusters in ennui at a time when motor activity is known to occur (Saint-Amant and Drapeau, 2000, 2001) further highlights the similarity of ennui phenotypes with those of mouse agrin knockouts. Therefore, the AChR phenotype observed in ennui strongly matches that in agrin-deficient animals. Since ennui is required in muscle, the ennui phenotype and the lack of response of mutant muscles to exogenous agrin suggest that the ennui gene product may play a role in agrin signaling by the muscle cells. Our complementation analysis showed that ennиi does not represent a mutation of the MuSK or Rapsyn genes, but it remains to be seen whether a mutation in another known gene in this clustering pathway is responsible for the ennui phenotype. Nevertheless, the presence of aneural clustering in еппиi mutants suggests that there is no wholesale disruption of the MuSK/DOK-7/Rapsyn mechanism but rather an inability of these molecular pathways to respond to agrin in ennui mutants.

\section{Dystroglycan and AChR Localization}

Defects in the dystrophin-glycoprotein complex of which dystroglycan is a member are implicated in many inherited human neuromuscular disorders (Barresi and Campbell, 2006). Studies in the mouse show that the complex is not required for the initiation of synaptic formation but is required for the maintenance and stability of NMJs (Grady et al., 2000; Jacobson et al., 2001). In zebrafish, the initial stages of the formation of synaptic AChR clusters are not affected by the knockdown of dystroglycan with normal synaptic clusters colocalizing with motor axons 
(Parsons et al., 2002). However, the residual distributed clustering of AChRs seen in unplugged mutants, which are nulls for zebrafish $M u S K$, at later larval stages is dependent on dystroglycan (Lefebvre et al., 2007) suggesting that dystroglycan operates during later stages of NMJ development. On the other hand, the ennui mutation affects earlier stages of NMJ development. Thus, results from unplugged and ennui mutants are in general agreement with findings in mammals that the agrin/MuSK pathway is critical for early formation of the NMJ, whereas dystroglycan is more important at later stages (Grady et al., 2000; Jacobson et al., 2001; Marangi et al., 2002; Taniguchi et al., 2006). It will be interesting to see whether ennui can be used to dissect the molecular nature of this transition from a young to a mature synapse.

An interesting feature of dystroglycan is that it is normally expressed at high levels in the ends of muscle fibers at the myotomal boundaries in zebrafish from the onset of muscle fiber development (Chambers et al., 2003). This is the same site where AChRs localize in ennui embryos, which suggests that the high level of dystroglycan at the myotome boundaries may be responsible for the aberrant localization of AChRs in the absence of the agrin initiated synaptic clustering in ennui mutants.

\section{Increased Motor Axon Branching and Functional Recovery in ennui Mutants}

Increased branching by motor axons has been observed in many mouse knockouts that affect the clustering of AChRs (DeChiara et al., 1996; Gautam et al., 1996; Fu et al., 2005; Okada et al., 2006; Weatherbee et al., 2006). The increased branching suggests that a decrease or absence of synaptic function at the NMJ caused by a muscle specific deficiency generally leads to a marked increase in motor axon branching. Genetic mosaic analysis demonstrated that the increased branching phenotype is cell non-autonomous in ennui as it was dependent on the genotype of the muscle cells, making the over branching phenotype seen in ennui very similar to the cases observed in mouse knockouts.

Interestingly, increased branching was most notable in the ends of fast-twitch fibers at the myotomal boundaries where AChRs are mislocalized. It would be interesting to see if the increased branching develops by selective extension of branches towards the ectopic receptors. This could be tested in future studies by performing in vivo time lapse imaging of axonal arbors and comparing the axonal growth patterns in mutants versus wild-types. There is a precedent for thinking that muscle cells can direct motor axon sprouting, indeed, time-lapse microscopic examination of pioneering motor growth cones in wild-type embryos recently showed that they appear to preferentially extend toward the prepatterned clusters of AChRs and consolidate the AChRs into stable NMJs (Flanagan-Steet et al., 2005; Panzer et al., 2006). This suggests the hypothesis that the mislocalized AChRs at the ends of fast-twitch fibers induce motor axons to branch towards them in ennui mutants and the ectopic branches, in turn, stabilize the mislocalized AChRs at these locations. The suppression of motor axon sprouting during AChR blockade in ennui embryos further suggests that activity plays a role in the increased branching observed. It would also be intriguing to examine whether the ectopic motor branches and AChRs form functional synapses. If so this might contribute to functional recovery and development into viable and fertile adults of ennui mutants. Additionally, later development of distributed NMJs due to the normal action of dystroglycan (Lefebvre et al., 2007) may also contribute to functional recovery in mutants.

Further analysis of the role of the ennui gene for regulation of AChRs awaits its molecular identification. The ennui gene appears to encode for a muscle factor required for agrin-mediated development of the NMJ. Genetic complementation with other zebrafish mutant lines showed that ennui is not MuSK/ unplugged (Zhang et al., 2004) nor Rapsyn/twitch once (Ono et al., 2002). In addition, mapping data ruled out 39 other genes implicated in the development of the NMJ, including agrin, dystroglycan-1, Abelson murine leukemia viral oncognee homolog 1 and 2 (abl-1 and -2), geranylgeranyl transferase (ggt), neuregulins, Erb receptors, and utrophin (see Table 1 for references). The molecular identification of the ennui gene holds the promise of increasing our understanding of the cascade initiated by agrin and clarify why prepatterned, nerve-independent AChR clusters are intact in ennui mutants, whereas the synaptic clusters are inhibited.

H.H. was supported by a Long Term Fellowship from the Human Frontiers of Science Program. We wish to thanks Dr. D. Goldman for the actin-GFP transgenic and Dr. J.R. Sanes for the HB9-mGFP line.

\section{REFERENCES}

Banks GB, Fuhrer C, Adams ME, Froehner SC. 2003. The postsynaptic submembrane machinery at the neuromuscular junction: Requirement for rapsyn and the utrophin/ 
dystrophin-associated complex. J Neurocytol 32:709726.

Barresi R, Campbell KP. 2006. Dystroglycan: From biosynthesis to pathogenesis of human disease. J Cell Sci 119:199-207.

Bowe MA, Mendis DB, Fallon JR. 2000. The small leucine-rich repeat proteoglycan biglycan binds to $\alpha$-dystroglycan and is upregulated in dystrophic muscle. $\mathrm{J}$ Cell Biol 148:801-810.

Burgess RW, Nguyen QT, Son YJ, Lichtman JW, Sanes JR. 1999. Alternatively spliced isoforms of nerve- and muscle-derived agrin: Their roles at the neuromuscular junction. Neuron 23:33-44.

Buss RR, Drapeau P. 2000. Physiological properties of zebrafish embryonic red and white muscle fibers during early development. J Neurophysiol 84:1545-1557.

Carmany-Rampey A, Moens CB. 2006. Modern mosaic analysis in the zebrafish. Methods 39:228-238.

Chambers SP, Anderson LV, Maguire GM, Dodd A, Love DR. 2003. Sarcoglycans of the zebrafish: Orthology and localization to the sarcolemma and myosepta of muscle. Biochem Biophys Res Commun 303:488-495.

Chen K, Featherstone DE. 2005. Discs-large (DLG) is clustered by presynaptic innervation and regulates postsynaptic glutamate receptor subunit composition in Drosophila. BMC Biol 3:1.

DeChiara TM, Bowen DC, Valenzuela DM, Simmons MV, Poueymirou WT, Thomas S, Kinetz E, et al. 1996. The receptor tyrosine kinase MuSK is required for neuromuscular junction formation in vivo. Cell 85:501-512.

Downes GB, Granato M. 2004. Acetylcholinesterase function is dispensable for sensory neurite growth but is critical for neuromuscular synapse stability. Dev Biol 270: 232-245.

Drapeau P, Ali DW, Buss RR, Saint-Amant L. 1999. In vivo recording from identifiable neurons of the locomotor network in the developing zebrafish. J Neurosci Methods $88: 1-13$.

Ferns M, Hoch W, Campanelli JT, Rupp F, Hall ZW, Scheller RH. 1992. RNA splicing regulates agrin-mediated acetylcholine receptor clustering activity on cultured myotubes. Neuron 8:1079-1086.

Ferns MJ, Hall ZW. 1992. How many agrins does it take to make a synapse? Cell 70:1-3.

Finn AJ, Feng G, Pendergast AM. 2003. Postsynaptic requirement for Abl kinases in assembly of the neuromuscular junction. Nat Neurosci 6:717-723.

Flanagan-Steet H, Fox MA, Meyer D, Sanes JR. 2005. Neuromuscular synapses can form in vivo by incorporation of initially aneural postsynaptic specializations. Development 132:4471-4481.

Francis MM, Evans SP, Jensen M, Madsen DM, Mancuso J, Norman KR, Maricq AV. 2005. The Ror receptor tyrosine kinase CAM-1 is required for ACR-16-mediated synaptic transmission at the $C$. elegans neuromuscular junction. Neuron 46:581-594.

Fu AK, Ip FC, Fu WY, Cheung J, Wang JH, Yung WH, Ip NY. 2005. Aberrant motor axon projection, acetylcholine receptor clustering, and neurotransmission in cyclin- dependent kinase 5 null mice. Proc Natl Acad Sci USA 102:15224-15229.

Fuhrer C, Gautam M, Sugiyama JE, Hall ZW. 1999. Roles of rapsyn and agrin in interaction of postsynaptic proteins with acetylcholine receptors. J Neurosci 19:6405-6416.

Gally C, Eimer S, Richmond JE, Bessereau JL. 2004. A transmembrane protein required for acetylcholine receptor clustering in Caenorhabditis elegans. Nature 431: 578-582.

Gautam M, Noakes PG, Moscoso L, Rupp F, Scheller RH, Merlie JP, Sanes JR. 1996. Defective neuromuscular synaptogenesis in agrin-deficient mutant mice. Cell 85:525-535.

Gautam M, Noakes PG, Mudd J, Nichol M, Chu GC, Sanes JR, Merlie JP. 1995. Failure of postsynaptic specialization to develop at neuromuscular junctions of rapsyn-deficient mice. Nature 377:232-236.

Glass DJ, Apel ED, Shah S, Bowen DC, DeChiara TM, Stitt TN, Sanes JR, et al. 1997. Kinase domain of the musclespecific receptor tyrosine kinase (MuSK) is sufficient for phosphorylation but not clustering of acetylcholine receptors: Required role for the MuSK ectodomain? Proc Natl Acad Sci USA 94:8848-8853.

Godfrey EW, Nitkin RM, Wallace BG, Rubin LL, McMahan UJ. 1984. Components of Torpedo electric organ and muscle that cause aggregation of acetylcholine receptors on cultured muscle cells. J Cell Biol 99:615-627.

Godfrey EW, Schwarte RC. 2003. The role of nitric oxide signaling in the formation of the neuromuscular junction. J Neurocytol 32:591-602.

Grady RM, Zhou H, Cunningham JM, Henry MD, Campbell KP, Sanes JR. 2000. Maturation and maintenance of the neuromuscular synapse: Genetic evidence for roles of the dystrophin-glycoprotein complex. Neuron 25:279293.

Guyon JR, Mosley AN, Jun SJ, Montanaro F, Steffen LS, Zhou Y, Nigro V, et al. 2005. $\Delta$-Sarcoglycan is required for early zebrafish muscle organization. Exp Cell Res 304:105-115.

Haffter P, Granato M, Brand M, Mullins MC, Hammerschmidt M, Kane DA, Odenthal J, et al. 1996. The identification of genes with unique and essential functions in the development of the zebrafish, Danio rerio. Development 123:1-36.

Haghighi AP, McCabe BD, Fetter RD, Palmer JE, Hom S, Goodman CS. 2003. Retrograde control of synaptic transmission by postsynaptic CaMKII at the Drosophila neuromuscular junction. Neuron 39:255-267.

Hamill OP, Marty A, Neher E, Sakmann B, Sigworth FJ. 1981. Improved patch-clamp techniques for high-resolution current recording from cells and cell-free membrane patches. Pflugers Arch 391:85-100.

Higashijima S, Okamoto H, Ueno N, Hotta Y, Eguchi G. 1997. High-frequency generation of transgenic zebrafish which reliably express GFP in whole muscles or the whole body by using promoters of zebrafish origin. Dev Biol 192:289-299.

Hoch W, Campanelli JT, Harrison S, Scheller RH. 1994. Structural domains of agrin required for clustering of nicotinic acetylcholine receptors. EMBO J 13:2814-2821. 
Hukriede NA, Joly L, Tsang M, Miles J, Tellis P, Epstein JA, Barbazuk WB, et al. 1999. Radiation hybrid mapping of the zebrafish genome. Proc Natl Acad Sci USA 96:9745-9750.

Jacobson C, Cote PD, Rossi SG, Rotundo RL, Carbonetto S. 2001. The dystroglycan complex is necessary for stabilization of acetylcholine receptor clusters at neuromuscular junctions and formation of the synaptic basement membrane. J Cell Biol 152:435-450.

Keshishian H, Kim YS. 2004. Orchestrating development and function: Retrograde BMP signaling in the Drosophila nervous system. Trends Neurosci 27:143-147.

Kim MJ, Liu IH, Song Y, Lee JA, Halfter W, Balice-Gordon RJ, Linney E, et al. 2006. Agrin is required for posterior development and motor axon outgrowth and branching in embryonic zebrafish. Glycobiology 17:231-247.

Kummer TT, Misgeld T, Sanes JR. 2006. Assembly of the postsynaptic membrane at the neuromuscular junction: Paradigm lost. Curr Opin Neurobiol 16:74-82.

Lacazette E, Le Calvez S, Gajendran N, Brenner HR. 2003. A novel pathway for MuSK to induce key genes in neuromuscular synapse formation. J Cell Biol 161:727-736.

Lefebvre JL, Jing L, Becaficco S, Franzini-Armstrong C, Granato M. 2007. Differential requirement for MuSK and dystroglycan in generating patterns of neuromuscular innervation. Proc Natl Acad Sci USA 104:2483-2488.

Lin W, Burgess RW, Dominguez B, Pfaff SL, Sanes JR, Lee KF. 2001. Distinct roles of nerve and muscle in postsynaptic differentiation of the neuromuscular synapse. Nature 410:1057-1064.

Lin W, Dominguez B, Yang J, Aryal P, Brandon EP, Gage FH, Lee KF. 2005. Neurotransmitter acetylcholine negatively regulates neuromuscular synapse formation by a Cdk5-dependent mechanism. Neuron 46:569-579.

Luo ZG, Je HS, Wang Q, Yang F, Dobbins GC, Yang ZH, Xiong WC, et al. 2003. Implication of geranylgeranyltransferase I in synapse formation. Neuron 40:703-717.

Luo ZG, Wang Q, Zhou JZ, Wang J, Luo Z, Liu M, He X, et al. 2002. Regulation of AChR clustering by Dishevelled interacting with MuSK and PAK1. Neuron 35:489505.

Madhavan R, Peng HB. 2005. Molecular regulation of postsynaptic differentiation at the neuromuscular junction. IUBMB Life 57:719-730.

Marangi PA, Wieland ST, Fuhrer C. 2002. Laminin-1 redistributes postsynaptic proteins and requires rapsyn, tyrosine phosphorylation, and Src and Fyn to stably cluster acetylcholine receptors. J Cell Biol 157:883-895.

Misgeld T, Kummer TT, Lichtman JW, Sanes JR. 2005. Agrin promotes synaptic differentiation by counteracting an inhibitory effect of neurotransmitter. Proc Natl Acad Sci USA 102:11088-11093.

Mook-Jung I, Gordon H. 1995. Acetylcholine receptor clustering in $\mathrm{C} 2$ muscle cells requires chondroitin sulfate. $\mathrm{J}$ Neurobiol 28:482-492.

Okada K, Inoue A, Okada M, Murata Y, Kakuta S, Jigami T, Kubo S, et al. 2006. The muscle protein Dok-7 is essential for neuromuscular synaptogenesis. Science 312:1802-1805.
Ono F, Shcherbatko A, Higashijima S, Mandel G, Brehm P. 2002. The Zebrafish motility mutant twitch once reveals new roles for rapsyn in synaptic function. $J$ Neurosci 22:6491-6498.

Panzer JA, Gibbs SM, Dosch R, Wagner D, Mullins MC, Granato M, Balice-Gordon RJ. 2005. Neuromuscular synaptogenesis in wild-type and mutant zebrafish. Dev Biol 285:340-357.

Panzer JA, Song Y, Balice-Gordon RJ. 2006. In vivo imaging of preferential motor axon outgrowth to and synaptogenesis at prepatterned acetylcholine receptor clusters in embryonic zebrafish skeletal muscle. J Neurosci 26:934947.

Parsons MJ, Campos I, Hirst EM, Stemple DL. 2002. Removal of dystroglycan causes severe muscular dystrophy in zebrafish embryos. Development 129:3505-3512.

Rimer M. 2007. Neuregulins at the neuromuscular synapse: Past, present, and future. J Neurosci Res 85:18271833.

Sadasivam G, Willmann R, Lin S, Erb-Vogtli S, Kong XC, Ruegg MA, Fuhrer C. 2005. Src-family kinases stabilize the neuromuscular synapse in vivo via protein interactions, phosphorylation, and cytoskeletal linkage of acetylcholine receptors. J Neurosci 25:1047910493.

Saint-Amant L, Drapeau P. 1998. Time course of the development of motor behaviors in the zebrafish embryo. $\mathrm{J}$ Neurobiol 37:622-632.

Saint-Amant L, Drapeau P. 2000. Motoneuron activity patterns related to the earliest behavior of the zebrafish embryo. J Neurosci 20:3964-3972.

Saint-Amant L, Drapeau P. 2001. Synchronization of an embryonic network of identified spinal interneurons solely by electrical coupling. Neuron 31:1035-1046.

Saint-Amant L, Drapeau P. 2003. Whole-cell patch-clamp recordings from identified spinal neurons in the zebrafish embryo. Methods Cell Sci 25:59-64.

Sanes JR, Lichtman JW. 1999. Development of the vertebrate neuromuscular junction. Annu Rev Neurosci 22:389442.

Slater CR. 2003. Structural determinants of the reliability of synaptic transmission at the vertebrate neuromuscular junction. J Neurocytol 32:505-522.

Strochlic L, Cartaud A, Labas V, Hoch W, Rossier J, Cartaud J. 2001. MAGI-1c: A synaptic MAGUK interacting with muSK at the vertebrate neuromuscular junction. $\mathrm{J}$ Cell Biol 153:1127-1132.

Taniguchi M, Kurahashi H, Noguchi S, Fukudome T, Okinaga T, Tsukahara T, Tajima Y, et al. 2006. Aberrant neuromuscular junctions and delayed terminal muscle fiber maturation in $\alpha$-dystroglycanopathies. Hum Mol Genet 15:1279-1289.

Wallace BG, Qu Z, Huganir RL. 1991. Agrin induces phosphorylation of the nicotinic acetylcholine receptor. Neuron 6:869-878.

Wang J, Jing Z, Zhang L, Zhou G, Braun J, Yao Y, Wang ZZ. 2003. Regulation of acetylcholine receptor clustering by the tumor suppressor APC. Nat Neurosci 6:10171018. 
Weatherbee SD, Anderson KV, Niswander LA. 2006. LDLreceptor-related protein 4 is crucial for formation of the neuromuscular junction. Development 133:49935000.

Westerfield M. 2000. The Zebrafish Book. A Guide for the Laboratory Use of Zebrafish (Danio rerio). Eugene: University of Oregon Press.

Westerfield M, Liu DW, Kimmel CB, Walker C. 1990. Pathfinding and synapse formation in a zebrafish mutant lacking functional acetylcholine receptors. Neuron 4: 867-874.
Westerfield M, McMurray JV, Eisen JS. 1986. Identified motoneurons and their innervation of axial muscles in the zebrafish. J Neurosci 6:2267-2277.

Weston C, Yee B, Hod E, Prives J. 2000. Agrin-induced acetylcholine receptor clustering is mediated by the small guanosine triphosphatases Rac and Cdc42. J Cell Biol 150:205-212.

Zhang J, Lefebvre JL, Zhao S, Granato M. 2004. Zebrafish unplugged reveals a role for muscle-specific kinase homologs in axonal pathway choice. Nat Neurosci 7:1303-1309. 